OPEN ACCESS

Edited by:

Melissa Orlandin Premaor,

Federal University of Minas Gerais,

Brazil

Reviewed by:

Katrina M. Williams,

University of Maryland, Baltimore,

United States

T. John Martin,

University of Melbourne, Australia

*Correspondence:

Ning Wang

n.wang@sheffield.ac.uk

Specialty section:

This article was submitted to

Bone Research,

a section of the journal

Frontiers in Endocrinology

Received: 19 November 2021

Accepted: 17 December 2021

Published: 07 January 2022

Citation:

Zhou Y, Arredondo HM and Wang N (2022) P2Y Receptors in Bone -

Anabolic, Catabolic, or Both?

Front. Endocrinol. 12:818499.

doi: 10.3389/fendo.2021.818499

\section{P2Y Receptors in Bone - Anabolic, Catabolic, or Both?}

\author{
Yuhan Zhou, Hector M. Arredondo and Ning Wang * \\ The Mellanby Centre for Musculoskeletal Research, Department of Oncology and Metabolism, The University of Sheffield, \\ Sheffield, United Kingdom
}

P2Y receptors, including eight subtypes, are G protein-coupled receptors that can be activated by extracellular nucleotides. Nearly all P2Y receptors are expressed in bone cells, suggesting their involvements in bone physiology and pathology. However, their exact roles in bone homeostasis are not entirely clear. Therefore, this mini review summarizes new research developments regarding individual P2Y receptors and their roles in bone biology, particularly detailing those which execute both anabolic and catabolic functions. This dual function has highlighted the conundrum of pharmacologically targeting these P2Y receptors in bone-wasting diseases. Further research in finding more precise targeting strategy, such as promoting anabolic effects via combining with physical exercise, should be prioritized.

Keywords: P2Y receptor, ATP, ADP, osteoblast, osteoclast

\section{INTRODUCTION}

Extracellular nucleotides, whether they are adenosine $5^{\prime}$-triphosphate (ATP), uridine 5'triphosphate (UTP), or their hydrolysate adenosine adenosine $5^{\prime}$-diphosphate (ADP), uridine- $5^{\prime}$ diphosphate (UDP) and UDP-sugars, have been identified as an essential class of signal molecules which can activate the purinergic signalling in diverse types of cells and tissues, thereby mediating biological events (1). Currently, extracellular nucleotides have been found to play key roles in a variety of physiological processes such as tissue homeostasis, wound healing, neurodegeneration, immunity, inflammation, and tumor metastasis (2). Importantly in bone, P2 receptors, purinergic receptors that bind nucleotides, can finely regulate bone cell physiology and modulate bone remodeling (3).

It was not until 1985 that $\mathrm{P} 2$ receptors were firstly distinguished into two purinoceptor subtypes based on their pharmacological characteristics: P2X and P2Y receptors (4), followed by further new subtypes such as P2T, P2Z, and P2U receptors $(5,6)$. In the following decade, to provide a more organized basis, $\mathrm{P} 2$ receptors had been re-categorized based on their transduction mechanisms and topology into two major families: the P2X family of ligand-gated ion channel receptors and the P2Y family of G protein-coupled receptors (GPCRs) (7).

To date, seven P2X receptor (P2XR1-7) members have been identified in human. As ligandgated ion channel receptors, their physiological agonists are mainly ATP. P2XRs were shown to form functional trimers with three ATP binding sites, all of which need to be occupied to trigger the channel opening and subsequently mediate selective permeability to cations, such as $\mathrm{Ca}^{2+}, \mathrm{Na}^{+}, \mathrm{K}^{+}$ $(8,9)$. In contrast, the GPCR P2YRs can be activated by adenine and uridine nucleotides. GPCRs 
have been found as therapeutic targets for a variety of human diseases and more than $40 \%$ of modern drugs are GPCRs based (10). Herein, we focus on the recent advances in our understanding of the involvement of P2Y receptors (P2YRs) in bone physiology and pathology.

\section{P2Y RECEPTORS}

There are eight members of P2YRs and can be divided into two subgroups based on their structure similarities: P2Y1-like GPCRs including P2Y1, P2Y2, P2Y4, P2Y6 and P2Y11; and P2Y12-like GPCRs including P2Y12, P2Y13 and P2Y14. In addition, there are also two non-mammalian $\mathrm{p} 2 \mathrm{y} 8$ and tp2y receptors (11). ADP, ATP, UDP, UTP and UDP-sugars have all been identified as agonists for P2YR (12). P2YRs are located on the cell membrane and consists of an extracellular N-terminus, an intracellular C-terminus and seven hydrophobic transmembrane helices connecting three intracellular and extracellular loops. Signaling via diverse G proteins activates or inhibits different pathways. The $\mathrm{Gq}$ alpha subunit (Gq/ 11 proteins) and $\mathrm{Gs}$ alpha subunit (Gos proteins) are stimulated through binding of extracellular nucleotides to P2Y1-like GPCRs, thereby leading to downstream signal cascade: the activation of phospholipase C/inositol 1,4,5trisphosphate $\left(\mathrm{PLC} / \mathrm{IP}_{3}\right)$ and adenylyl cyclase (AC) pathway, respectively. Compared with P2Y1-like GPCRs, P2Y12-like GPCRs bind to Gi protein alpha subunit (Gi/Go proteins) inhibiting AC pathway resulting in decreased accumulation of cyclic adenosine monophosphate (cAMP) and cAMP-dependent protein kinase (PKA) (Figure 1) (13). P2YRs can form multimers in certain circumstances as P2XRs do, but their peptides show lower sequence homology (19-55\%) compared to P2XR. Thus, P2YRs have a greater diversity in their pharmacological and operational profiles $(8,14)$.

\section{P2YRs IN BONE}

Bone is a specialized connective tissue that provides internal support in all higher vertebrates. It makes up the skeletal system, together with cartilage $(15,16)$. In bone, extracellular matrix and cells are the fundamental constituents. The organic matrix is mainly composed of Type I collagen. This matrix is strengthened by inorganic component, mainly carbonated hydroxyapatite. Bone is composed of four different cell types: osteoblast, osteoclast, osteocyte and bone lining cells. Those bone cells together play essential roles in the process of bone modeling and remodeling (16).

The investigation of the role of P2YRs in bone cells can be traced back to early 1990s. Evidence was found for the presence of P2 purinoceptors on both rat and human osteoblast-like cells (17, 18), and P2YRs were shown to mediate the non-selective cation channels and $\mathrm{Ca}^{2+}$ dependent $\mathrm{K}^{+}$channels in rat osteoclasts (19). Since then, an increasing number of purinoceptor subtypes were found existing in human bone related cells, by means of

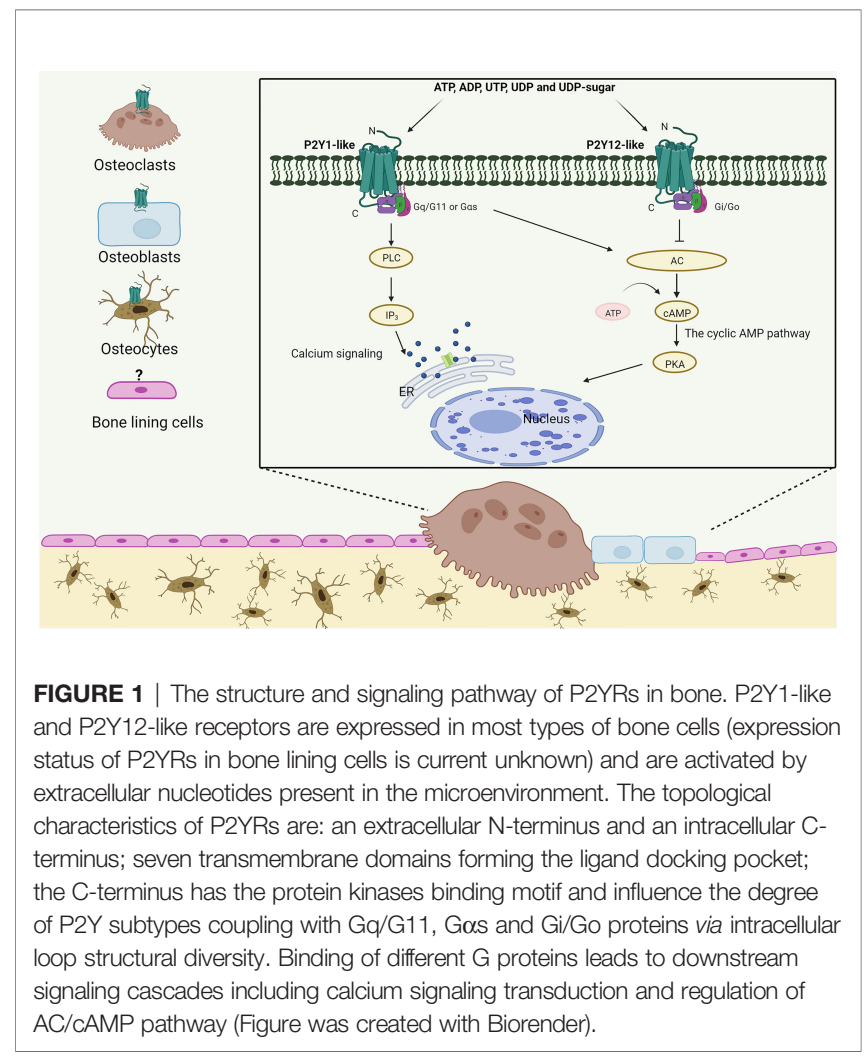

immunocytochemistry, in situ hybridization, and RT-PCR (20). In the bone microenvironment, nucleotides are intracellularly presented at a normal concentration of $2-5 \mathrm{mM}$ but released into extracellular under mechanical stimulation, tissue injury or inflammation situations (21). These extracellular nucleotides are then able to regulate bone remodeling as extracellular signaling molecules, such as functioning as mitogens for osteoblasts and osteoclasts, via binding to $\mathrm{P} 2$ receptors. Activation of $\mathrm{P} 2 \mathrm{Y}$ receptors will couple to downstream signal transduction cascades, including cAMP/PKA pathway and/or $\mathrm{IP}_{3}$ hydrolysis by PLC and subsequent release of $\mathrm{Ca}^{2+}$ from endoplasmic reticulum (ER) (3). The high concentration of $\mathrm{Ca}^{2+}$ will induce the activation of the mitogen-activated protein kinase (MAPK) pathway via phosphorylation of extracellular signal-regulated kinase (ERK), especially ERK 1/2 (22).

However, due to the variability of P2YR subtypes, different subtypes play different roles during bone homeostasis, which correlate to their native agonists, binding $G$ protein type, and expression in different bone cells (Table 1). Based on the last comprehensive review by Orriss et al. in 2012 (20), we will next review most recent research progress in roles of each individual P2YR subtypes in bone cell biology and bone homeostasis.

\section{P2Y1-Like Receptors}

The Gq/11-coupled P2Y1 receptor is predominantly activated by ADP, whilst ATP can act as its antagonist or partial agonist (51). P2Y1Rs were initially found to be mainly involved in the regulation of osteoclast-mediated bone loss. 2-MethylthioADP (2-MeSADP) was developed as a highly selective P2Y1R agonist 
TABLE 1 | Distribution and characteristics of P2 receptors in bone.

\begin{tabular}{|c|c|c|c|c|}
\hline Receptor & Native Agonists & $\begin{array}{l}\text { Binding G } \\
\text { protein type }\end{array}$ & Main distribution in bone & Functional effects \\
\hline $\mathrm{P} 2 \mathrm{Y} 1$ & ADP $>$ ATP & $\mathrm{Gq} / 11$ & Osteoblasts and osteoclasts & $\begin{array}{l}\text { Enhance PTH-induced } \mathrm{Ca}^{2+} \text { signaling and ultrasound-induced osteoblast proliferation } \\
(3,23-25) . \\
\text { Increase the osteoclast formation and resorption (26). } \\
\text { Involve in the mechanotransduction (27). }\end{array}$ \\
\hline P2Y2 & UTP $=>$ ATP & $\mathrm{Gq} / 11$ & $\begin{array}{l}\text { Osteoblasts, osteoclasts } \\
\text { and osteocytes. }\end{array}$ & $\begin{array}{l}\text { Inhibit differentiation and mineralization of osteoblasts (28-32). } \\
\text { Induce bone resorption from osteoclasts (32). } \\
\text { Propagation of intercellular } \mathrm{Ca}^{2+} \text { waves }(33) \text { and involve in mechanotransduction }(27,34) \text {. }\end{array}$ \\
\hline P2Y4 & UTP $=>$ ATP & $\mathrm{Gq} / 11$ & $\begin{array}{l}\text { Osteoblasts and } \\
\text { osteocytes. }\end{array}$ & Play a 'off-switch' role during bone formation with P2Y2R (35). \\
\hline P2Y6 & UDP $>$ UTP $>>$ ATP & $\mathrm{Gq} / 11$ & $\begin{array}{l}\text { Osteoblasts, osteoclasts } \\
\text { and osteocytes. }\end{array}$ & $\begin{array}{l}\text { Contribute to osteoclast resorption (36) and enhance osteoclast survival (37). } \\
\text { Induce osteogenic differentiation from BMSCs (38). } \\
\text { Involve in mechanotransduction (27). }\end{array}$ \\
\hline P2Y11 & ATP/UTP & $\mathrm{Gq} / 11$ and $\mathrm{G} \alpha \mathrm{s}$ & Osteoclasts & Inhibit cell migration and bone metastasis in breast cancer (39). \\
\hline P2Y12 & $A D P>>A T P$ & Gi/Go & $\begin{array}{l}\text { Osteoblasts, osteoclasts } \\
\text { and osteocytes. }\end{array}$ & $\begin{array}{l}\text { Induce osteoblastogenesis and avoid osteoclasts formation }(40,41) \text { but others } \\
\text { suggested maintaining osteoclasts activity }(42) \text {. }\end{array}$ \\
\hline $\mathrm{P} 2 \mathrm{Y} 13$ & ADP $>>A T P$ & Gi/Go & $\begin{array}{l}\text { Osteoblasts, osteoclasts } \\
\text { and osteocytes. }\end{array}$ & $\begin{array}{l}\text { Induce osteoblasts differentiation and osteoclastogenesis (43-47). } \\
\text { involve in mechanotransduction (27). }\end{array}$ \\
\hline $\mathrm{P} 2 \mathrm{Y} 14$ & UDP-sugar/UDP & $\mathrm{Gi} / \mathrm{Go}$ & Osteoblasts and osteoclasts & $\begin{array}{l}\text { Promote osteoclastogenesis }(48,49) \\
\text { Promote osteoblast proliferation (50). } \\
\text { Involved in mechanotransduction (27). }\end{array}$ \\
\hline
\end{tabular}

which mimic ADP and lead to P2Y1R-mediated cell responses (52). This agonist can stimulate osteoclast formation and resorptive activity at a concentration of only $0.1-10 \mu \mathrm{M}$ (26). Meanwhile, P2Y1Rs were found to be expressed at transcriptional and translational levels in both osteoblasts and osteoclasts. P2Y1R is reported to modulate osteoblastic responses to systemic factors such as parathyroid hormone (PTH) through up-regulating the phosphorylation of cAMP response elementbinding protein and c-fos expression (23). ATP acts as the locally released costimulant to enhance $\mathrm{Ca}^{2+}$ release in response to $\mathrm{PTH}$, through activation of P2Y1R $(3,23)$. Besides, another study suggested that P2Y1R was stimulated by ATP released from osteoblasts after ultrasound induction, which acts in an autocrine manner to induce osteoblastogenesis (24). Further in vivo studies underscored the important role of P2Y1R in osteoblastic biology owing to the availability of P2Y1 knockout (KO) mice. Twomonth-old global P2Y1R KO mice showed 5-14\% decrease in bone mineral density (BMD) and bone mineral content (BMC) determined using DEXA scan. Significant decreases in trabecular parameters were detected through Micro-CT analysis (25). These findings indicate that, although predominantly plays a pro-osteogenic role, the P2Y1R may also regulate osteoclast differentiation.

In contrast to P2Y1R, P2Y2R has initially been suggested to play an inhibitory role in bone mineralization (28), as the activation of P2Y2R was shown to strongly inhibit bone nodule formation and mineralization of primary rat osteoblasts, without affecting the production of fibrous or soluble collagen $(29,30)$. Recent studies have shown that UTP inhibited osteogenic differentiation by activating P2Y2R in bone marrow-derived stromal cells via ERK1/2 pathway (31). Consistently, Orriss et al. showed increased bone formation by osteoblasts from P2Y2-KO mice which supported the notion of $\mathrm{P} 2 \mathrm{Y} 2 \mathrm{R}$ as a negative regulator of bone mineralization. They also found that defective resorption and decreased basal ATP release level in osteoclasts were present in $\mathrm{P} 2 \mathrm{Y} 2-\mathrm{KO}$ mice (32). In contrast, a study using P2Y2R-KO mice on a different genetic background (SV129) showed an anti-osteogenic phenotype (34), whilst in a rat model, P2Y2R overexpression led to altered bone remodeling but mix phenotype, including enhanced bone length and strength but reduced trabecular thickness (53). Interestingly, this inconsistence was also evidenced in single nucleotide polymorphisms (SNPs) human cohort studies which clear associations between P2Y2R SNPs and bone mineral density (BMD) was established. In a Danish osteoporosis prevention study cohort, gain-of-function P2Y2R Arg312Ser SNP is correlated with higher BMD (54), while in a cohort of Dutch fracture patients, this correlation was not observed (55). Nevertheless, despite of these discrepancies, there is a consensus that the primary action of $\mathrm{P} 2 \mathrm{Y} 2 \mathrm{R}$ regulates mechanotransduction and extracellular ATP levels in bone. $\mathrm{P} 2 \mathrm{Y} 2 \mathrm{R}$ was first discovered to mediate the propagation of intercellular $\mathrm{Ca}^{2+}$ waves in osteoblasts in an autocrine manner after mechanical stimulation (33). Mechanistically, activation of P2Y2R in osteoblasts was found to sensitize mechanical stressactivated calcium influx as well as fast activation of multiple intracellular signaling pathways, including ERK1/2 and p38/ MAPK, protein kinase C (PKC), RhoA GTPase and c-Jun Nterminal kinases (JNK1) (56-60). Using P2Y2R KO murine cells, Xing et al. demonstrated that $\mathrm{KO}$-osteoblasts had reduced response, in terms of ERK1/2 phosphorylation, to both ATP and mechanical stimulation (34). In osteoclast, P2Y2R activation, whether acute or long-term, both promoted the release of ATP from osteoclasts, which indicates that the $\mathrm{P} 2 \mathrm{Y} 2 \mathrm{R}$ possibly regulate osteoclast function indirectly by promoting ATP release (32). In short, although the role of P2Y2R in bone homeostasis is possibly genetic background or species dependent, it has a primary role of regulating 
mechanotransduction and extracellular ATP release in bone cells.

Unlike P2Y2R, the molecular mechanisms of P2Y4R involvement in regulating bone cells are still unclear, despite both P2YRs are Gq/11 coupled receptors activated by UTP. It was only suggested that P2Y4R may play a 'off-switch' role during bone formation with redundancy of function of P2Y2R (35).

P2Y6R, which is selectively stimulated by UDP, has been found to be expressed in osteoclasts. UDP, released from mechanical stimulation or inflammation, can act through P2Y6R to induces the translocation and activation of NFKB in osteoclasts and their precursors, preventing apoptosis induced by TNF $\alpha$ pathway (37). To further investigate the role of P2Y6R in osteoclasts, Orriss et al. found functional defects in osteoclasts derived from P2Y6R-KO mice. The histomorphometric analysis showed that surfaces of endocortical and trabecular bone tissue occupied by osteoclasts were reduced in P2Y6R-KO mice (36). However, in another study, selective activation of P2Y6R by the UDP analog PSB0474 promoted the osteogenic differentiation from human bone marrow stromal cells (BMSCs) in postmenopausal women. After selectively blocking P2Y6R, decreased osteogenic differentiation were found at all culture time points. This suggests that targeting P2Y6R may cause harm to osteoblasts and subsequently lead to more bone loss in postmenopausal osteoporosis (38).

Currently, very limited studies have been done to investigate the involvement of P2Y11R in bone. P2Y11R has been so far identified to be expressed in human osteoclasts, but its molecular mechanism and functions are still not clear (61). More recently, P2Y11R has been found to be involved in breast cancer bone metastasis. Liu et al. suggested that ATP released from osteocytes hemichannels bound P2Y11R thereby suppressing the expression of chemokine receptor CXCR4, resulting in the inhibition of cell migration and bone metastasis of breast cancer (39). In fact, the most common skeletal complication of breast cancer is osteolytic bone metastasis mediated by osteoclasts (62). This could underscore the connection between P2Y11R's expression in osteoclasts and the osteoclast-oriented formation of pre-metastasis niche and bone tropism of cancer cells, which warrant further investigation.

\section{P2Y12-Like Receptors}

P2Y12-like receptors have long been in the focus of skeletal disease as they mediate more key regulatory genes in the context of bone. Abnormal function of P2Y12-like receptors causes distinct bone phenotype like bone loss.

The Gi/Go-coupled receptor P2Y12R has been found to be expressed in both osteoblasts and osteoclasts. Syberg et al. demonstrated that clopidogrel, an antagonist of $\mathrm{P} 2 \mathrm{Y} 12 \mathrm{R}$, not only inhibited osteoblastogenesis, but also reduced the bone mass and strength by $\sim 20 \%$ in mice (40). This was further confirmed in a patient cohort study in which treatment with clopidogrel led to a $60 \%$ increase in risk of fractures (41). However, conflicted results were shown by $\mathrm{Su}$ et al. In this study, mice treated with clopidogrel were protected from pathologic osteolysis. P2Y12R-KO mice were partially protected from age-related and pathological bone loss with reduced osteoclast function, suggesting a pro-resorption role of P2Y12R possibly via the Ras-related protein (RAP1) signaling $(42,63)$. Therefore, whether the predominant function of $\mathrm{P} 2 \mathrm{Y} 12 \mathrm{R}$ in bone is pro-formation or pro-resorption remains to be investigated.

As another Gi/Go-coupled receptor, P2Y13R has high affinity for ADP. In the past decades, more functions of P2Y13R in maintaining bone homeostasis have been gradually revealed, confirming its potential role in the process of fighting bone diseases. The expression of P2Y13R in osteoblasts and osteoclasts were firstly confirmed in 2010 (24). Its downstream signaling pathway involves Ras homolog gene family member A (RhoA)/Rho-associated and coiled-coil containing protein kinase I (ROCK I) signaling, which were inhibited after P2Y13 depletion and in turn reduced the MAPK/ERK signaling pathway and osteoblasts differentiation $(43,44)$. Consistent with these findings, Biver et al. showed that ADP stimulated the activity of transcription factor Runx2 via the RhoA/ROCK1 signaling pathway in a P2Y13R-dependent way, thereby stimulating the differentiation of pre-osteoblasts to osteoblasts. P2Y13R was proposed as the main receptor mediating the balance of osteoblast and adipocyte terminal differentiation from bone marrow progenitors (45). Further studies using P2Y13R KO mice demonstrated that P2Y13R deficiency in mature mice resulted in an abnormal bone phenotype, including less trabecular bone but thicker cortical bone. This was a consequence of reduced rates of bone turnover caused by decreased number and function of both osteoblasts and osteoclasts, confirmed by both in vivo and in vitro data (44). In addition, KO mice showed a higher osteogenic response against non-invasive axial mechanical loading due to the lack of a P2Y13R-regulated negative feedback pathway for ATP release, which was supported by in vitro evidence suggesting reduced extracellular ATP degradation by ALP in KO primary osteoblasts. More interestingly, $\mathrm{KO}$ mice also appeared to be protected from estrogen-deficiency induced bone loss (46). These findings offer an inspiring prospect for P2Y13R based osteoporosis therapy which may combine anti-P2Y13 receptor drugs with exercise to provided anti-resorptive and anabolic effects simultaneously. Furthermore, P2Y13R also plays a critical role in skeletal development via coordinating with hormonal regulators of phosphate homeostasis. Increased osteoblasts and decreased osteoclasts were observed in 4weeks old young mice, whilst mature mice ( $>10$ weeks old) showed an opposite phenotype. This age-dependent skeletal phenotype change has been considered to be related to higher serum fibroblast growth factor-23 (FGF-23) and phosphorus levels. Thus, P2Y13R were thought to regulate bone development in two different ways, which are the endocrine regulation of phosphate and FGF23 homeostasis at younger ages and the direct regulation of bone cells through bone remodeling at mature age (47). With evidence mentioned above, it is plausible that the P2Y13R can not only be considered as a potential pharmacological target for the treatment of osteoporosis, but also provide a promising target for 
treating phosphate metabolism-related bone diseases, including hypo- and hyperphosphatemia.

$\mathrm{P} 2 \mathrm{Y} 14 \mathrm{R}$ is the only $\mathrm{P} 2 \mathrm{Y}$ receptor that can be stimulated by UDP-sugars but not ATP, UTP, and other naturally occurring diphosphate or triphosphate nucleotides (64). Evidence suggested that that extracellular UDP-sugars promoted expression of bone marrow receptor activator of NF- $\kappa B$ ligand (RANKL) and potentiated RANKL-induced osteoclastogenesis $(48,49)$. Lee et al. also found that the expression of P2Y14R can be selectively induced during RANKL-induced osteoclastogenesis both at the transcriptional and translational levels, while the protein expression of P2Y14R was downregulated when MAPK pathway was inhibited. More intriguingly, downregulation of P2Y14R by RNA interference (RNAi) was shown to suppress osteoclastogenesis (48). These data have clearly demonstrated a pro-osteoclastogenesis role for P2Y14R, whilst more recent evidence also suggested the involvement of P2Y14R in osteoblast biology. Using two murine osteoblast cell models, Mikolajewicz et al. found that P2Y14R negatively correlated with the efficiency of calcium signaling in response to mechanical and purinergic stimulation, but positively stimulated osteoblast proliferation possibly via modulating P2Y14-dependent ERK1/2 and AMPK $\alpha$ phosphorylation. Further data suggested that P2Y14R was also involved in osteogenic differentiation but its exact role needs further clarification (50). Although P2Y14R's dual role in promoting osteoclast formation and osteoblast proliferation might dampen its potential as a therapeutic target for treating bone wasting diseases, its involvement in osteoblastic responsiveness to mechanical stimulation is still of great scientific interest and may offer a prospective opportunity in enhancing the anabolic effect of exercise in bone.

\section{DISCUSSION}

Although the molecular mechanisms of P2YRs' involved in bone biology still need further elucidation, it is plausible that significant progress has been made in recent years. It is now clear that most of P2YRs play a dual role of both anabolic and catabolic functions during bone remodeling by affecting osteoblast and osteoclast simultaneously. To further fully understand the role of extracellular nucleotides-P2YRs

\section{REFERENCES}

1. Moore DJ, Chambers JK, Wahlin J-P, Tan KB, Moore GB, Jenkins O, et al. Expression Pattern of Human P2Y Receptor Subtypes: A Quantitative Reverse Transcription-Polymerase Chain Reaction Study. Biochim Biophys Acta - Gene Struct Expr (2001) 1521:107-19. doi: 10.1016/S0167-4781(01) 00291-3

2. Giuliani AL, Sarti AC, Di Virgilio F. Extracellular Nucleotides and Nucleosides as Signalling Molecules. Immunol Lett (2019) 205:16-24. doi: 10.1016/j.imlet.2018.11.006

3. Bowler WB, Buckley KA, Gartland A, Hipskind RA, Bilbe G, Gallagher JA. Extracellular Nucleotide Signaling: A Mechanism for Integrating Local and Systemic Responses in the Activation of Bone Remodeling. Bone (2001) 28:507-12. doi: 10.1016/S8756-3282(01)00430-6 signaling in the process of bone homeostasis, future research should elucidate the specific contribution of individual P2YRs in all types of bone cells including osteocytes and bone lining cells. No studies have yet revealed the expression of P2YRs in bone lining cells. Although P2Y2R, P2Y4R, P2Y6R, P2Y12R, and $\mathrm{P} 2 \mathrm{Y} 13 \mathrm{R}$ have been shown to be expressed in osteocytes, their roles in regulating the function of osteocytes are still unclear (65). Osteocytes are not only the most abundant type of bone cells but also the main mechanosensors within the bone. With their ligands-extracellular nucleotides being one of the main transduction signals of mechanical stimulation, several P2YRs, mainly P2Y2R, P2Y6R, P2Y13R, and P2Y14R, have being shown to be major players in regulating mechanotransduction. Therefore, further clarifying P2YRs' roles in osteocytes and mechanotransduction will bring in potential scientific and clinical benefits, such as enhancing the anabolic effect of exercise in bone via targeting P2Y2Rs. Furthermore, the availability of global P2YR-KO rodent models and specific antagonists have provided us powerful tools in investigating P2YRs in bone. However, due to variable subtypes of P2YRs existing on bone cells and their complex cell/tissue/ specie/age dependent functions, more specific research, such as examining the dynamic interaction and redundancy among all $\mathrm{P} 2 \mathrm{YRs}$ and using tissue-specific conditional P2Y-KO murine model with higher physiological relevance, are needed in the future. In addition, more patient cohort studies, such as research in P2YR SNPs and osteoporosis/fracture risks, are also warranted to verify all pre-clinical findings in human settings before candidate P2YRs based targets enter the long and costly drug development pipelines. Finally, due to the nature of their ligands being extracellular nucleotides, which are keys to fundamental pathophysiological processes such as inflammation and cancer, P2YRs should be further researched in other bone diseases, particularly, osteoarthritis and cancer induced bone disease.

\section{AUTHOR CONTRIBUTIONS}

YZ: Conceptualization, Writing - Original Draft; HA: Visualization, Writing - Review \& Editing; NW: Conceptualization, Supervision, Writing - Review \& Editing. All authors contributed to the article and approved the submitted version.

4. Burnstock G, Kennedy C. Is There a Basis for Distinguishing Two Types of P2-Purinoceptor? Gen Pharmacol Vasc Syst (1985) 16:433-40. doi: 10.1016/ 0306-3623(85)90001-1

5. Gordon RM. Folk Psychology as Simulation. Mind \& Lang (1986) 1:158-71. doi: 10.1111/j.1468-0017.1986.tb00324.x

6. O'Connor GT, Plume SK, Olmstead EM, Coffin LH, Morton JR, Maloney CT, et al. A Regional Prospective Study of In-Hospital Mortality Associated With Coronary Artery Bypass Grafting. JAMA (1991) 266:803-9. doi: 10.1001/ jama.1991.03470060065028

7. Abbracchio MP, Burnstock G. Purinoceptors: Are There Families of P2X and P2Y Purinoceptors? Pharmacol Ther (1994) 64:445-75. doi: 10.1016/01637258(94)00048-4

8. Burnstock G. Introduction: P2 Receptors. Curr Top Med Chem (2005) 4:793803. doi: $10.2174 / 1568026043451014$ 
9. Hattori M, Gouaux E. Molecular Mechanism of ATP Binding and Ion Channel Activation in P2X Receptors. Nature (2012) 485:207-12. doi: 10.1038/nature11010

10. Sriram K, Insel PA. G Protein-Coupled Receptors as Targets for Approved Drugs: How Many Targets and How Many Drugs? Mol Pharmacol (2018) 93:251-8. doi: 10.1124/mol.117.111062

11. von Kügelgen I, Wetter A. Molecular Pharmacology of P2Y-Receptors. Naunyn Schmiedebergs Arch Pharmacol (2000) 362(4-5):310-23. doi: $10.1007 / \mathrm{s} 002100000310$

12. Jacobson KA, Balasubramanian R, Deflorian F, Gao ZG. G Protein-Coupled Adenosine (P1) and P2Y Receptors: Ligand Design and Receptor Interactions. Purinergic Signal (2012) 8:419-36. doi: 10.1007/s11302-012-9294-7

13. Lovászi M, Branco Haas C, Antonioli L, Pacher P, Haskó G. The Role of P2Y Receptors in Regulating Immunity and Metabolism. Biochem Pharmacol (2021) 187:114419. doi: 10.1016/j.bcp.2021.114419

14. Burnstock G. Purine and Pyrimidine Receptors. Cell Mol Life Sci (2007) 64:1471-83. doi: 10.1007/s00018-007-6497-0

15. Weatherholt AM, Fuchs RK, Warden SJ. Specialized Connective Tissue: Bone, the Structural Framework of the Upper Extremity. J Handb Ther (2012) 25:123-32. doi: 10.1016/j.jht.2011.08.003

16. Florencio-Silva PCR, Sasso G, Sasso-Cerri E, Simões M. Biology of Bone Tissue: Structure, Function, and Factors That Influence Bone Cells. BioMed Res Int (2015) 2015:1-17. doi: 10.1155/2015/421746

17. Kumagai H, Sacktor B, Filburn CR. Purinergic Regulation of Cytosolic Calcium and Phosphoinositide Metabolism in Rat Osteoblast-Like Osteosarcoma Cells. J Bone Miner Res (1991) 6:697-708. doi: 10.1002/ jbmr.5650060707

18. Schöfl C, Cuthbertson KSR, Walsh CA, Mayne C, Cobbold P, von Zur Mühlen A, et al. Evidence for P2-Purinoceptors on Human Osteoblast-Like Cells. J Bone Miner Res (1992) 7:485-91. doi: 10.1002/jbmr.5650070504

19. Weidema AF, Barbera J, Dixon SJ, Sims SM. Extracellular Nucleotides Activate Non-Selective Cation and Ca2+-Dependent $\mathrm{K}+$ Channels in Rat Osteoclasts. J Physiol (1997) 503:303-15. doi: 10.1111/j.1469-7793.1997.303bh.x

20. Orriss IR, Arnett TR. P2Y Receptors in Bone. Wiley Interdiscip Rev Membr Transp Signal (2012) 1:805-14. doi: 10.1002/wmts.67

21. Hoebertz A, Arnett TR, Burnstock G. Regulation of Bone Resorption and Formation by Purines and Pyrimidines. Trends Pharmacol Sci (2003) 24:2907. doi: 10.1016/S0165-6147(03)00123-8

22. Liu D, Genetos DC, Shao Y, Geist DJ, Li J, Ke HZ, et al. Activation of Extracellular-Signal Regulated Kinase (ERK1/2) by Fluid Shear Is Ca2+- and ATP-Dependent in MC3T3-E1 Osteoblasts. Bone (2008) 42:644-52. doi: 10.1016/j.bone.2007.09.058

23. Buckley KA, Wagstaff SC, McKay G, Gaw A, Hipskind RA, Bilbe G, et al. Parathyroid Hormone Potentiates Nucleotide-Induced [Ca2+] I Release in Rat Osteoblasts Independently of Gq Activation or Cyclic Monophosphate Accumulation: A Mechanism for Localizing Systemic Responses in Bone. J Biol Chem (2001) 276:9565-71. doi: 10.1074/jbc.M005672200

24. Costa Alvarenga É, Rodrigues R, Caricati-Neto A, Silva-Filho FC, ParedesGamero EJ, Ferreira AT. Low-Intensity Pulsed Ultrasound-Dependent Osteoblast Proliferation Occurs by via Activation of the P2Y Receptor: Role of the P2Y1 Receptor. Bone (2010) 46:355-62. doi: 10.1016/j.bone.2009.09.017

25. Orriss IR, Evans HR, Gartland A, Arnett TR. MicroCT Analysis of P2Y1 and P2Y2 Receptor Knockout Mice Demonstrates Significant Changes in Bone Phenotype. Calcif Tissue Int (2008) 83:2-3.

26. Hoebertz A, Meghji S, Burnstock G, Arnett TR. Extracellular ADP Is a Powerful Osteolytic Agent: Evidence for Signaling Through the P2Y 1 Receptor on Bone Cells. FASEB J (2001) 15:1139-48. doi: 10.1096/fj.000395com

27. Kong Q, Quan Y, Tian G, Zhou J, Liu X. Purinergic P2 Receptors: Novel Mediators of Mechanotransduction. Front Pharmacol (2021) 12:1099. doi: 10.3389/fphar.2021.671809

28. Orriss IR, Key ML, Hajjawi MOR, Arnett TR. Extracellular ATP Released by Osteoblasts Is A Key Local Inhibitor of Bone Mineralisation. PloS One (2013) 8:1-13. doi: 10.1371/journal.pone.0069057

29. Hoebertz A, Mahendran S, Burnstock G, Arnett TR. ATP and UTP at Low Concentrations Strongly Inhibit Bone Formation by Osteoblasts: A Novel Role for the P2Y2 Receptor in Bone Remodeling. J Cell Biochem (2002) 86:413-9. doi: $10.1002 /$ jcb.10236
30. Orriss IR, Utting JC, Brandao-Burch A, Colston K, Grubb BR, Burnstock G, et al. Extracellular Nucleotides Block Bone Mineralization In Vitro: Evidence for Dual Inhibitory Mechanisms Involving Both P2Y2 Receptors and Pyrophosphate. Endocrinology (2007) 148:4208-16. doi: 10.1210/en.20070066

31. Li W, Wei S, Liu C, Song M, Wu H, Yang Y. Regulation of the Osteogenic and Adipogenic Differentiation of Bone Marrow-Derived Stromal Cells by Extracellular Uridine Triphosphate: The Role of P2Y2 Receptor and ERK1/ 2 Signaling. Int J Mol Med (2016) 37:63-73. doi: 10.3892/ijmm.2015.2400

32. Orriss IR, Guneri D, Hajjawi MOR, Shaw K, Patel JJ, Arnett TR. Activation of the P2Y2 Receptor Regulates Bone Cell Function by Enhancing ATP Release. J Endocrinol (2017) 233:341-56. doi: 10.1530/JOE-17-0042

33. Jørgensen NR, Geist ST, Civitelli R, Steinberg TH. ATP- and Gap JunctionDependent Intercellular Calcium Signaling in Osteoblastic Cells. J Cell Biol (1997) 139:497-506. doi: 10.1083/jcb.139.2.497

34. Xing Y, Gu Y, Bresnahan JJ, Paul EM, Donahue HJ, You J. The Roles of P2Y2 Purinergic Receptors in Osteoblasts and Mechanotransduction. PloS One (2014) 9:1-8. doi: 10.1371/journal.pone.0108417

35. Orriss IR, Knight GE, Ranasinghe S, Burnstock G, Arnett TR. Osteoblast Responses to Nucleotides Increase During Differentiation. Bone (2006) 39:300-9. doi: 10.1016/j.bone.2006.02.063

36. Orriss IR, Wang N, Burnstock G, Arnett TR, Gartland A, Robaye B, et al. The P2Y6 Receptor Stimulates Bone Resorption by Osteoclasts. Endocrinology (2011) 152:3706-16. doi: 10.1210/en.2011-1073

37. Korcok J, Raimundo LN, Du X, Sims SM, Dixon SJ. P2Y6 Nucleotide Receptors Activate NF- $\mathrm{kb}$ and Increase Survival of Osteoclasts. J Biol Chem (2005) 280:16909-15. doi: 10.1074/jbc.M410764200

38. Noronha-Matos JB, Costa MA, Magalhães-Cardoso MT, Ferreirinha F, Pelletier J, Freitas R, et al. Role of Ecto-NTPDases on UDP-Sensitive P2Y6 Receptor Activation During Osteogenic Differentiation of Primary Bone Marrow Stromal Cells From Postmenopausal Women. J Cell Physiol (2012) 227:2694-709. doi: 10.1002/jcp.23014

39. Liu X, Riquelme MA, Tian Y, Zhao D, Acosta FM, Gu S, et al. ATP Inhibits Breast Cancer Migration and Bone Metastasis Through Down-Regulation of CXCR4 and Purinergic Receptor P2y11. Cancers (Basel) (2021) 13:4293. doi: $10.3390 /$ cancers 13174293

40. Syberg S, Brandao-Burch A, Patel JJ, Hajjawi M, Arnett TR, Schwarz P, et al. Clopidogrel (Plavix), a P2Y12 Receptor Antagonist, Inhibits Bone Cell Function In Vitro and Decreases Trabecular Bone In Vivo. J Bone Miner Res (2012) 27:2373-86. doi: 10.1002/jbmr.1690

41. Jørgensen NR, Grove EL, Schwarz P, Vestergaard P. Clopidogrel and the Risk of Osteoporotic Fractures: A Nationwide Cohort Study. J Intern Med (2012) 272:385-93. doi: 10.1111/j.1365-2796.2012.02535.x

42. Su X, Floyd DH, Hughes A, Xiang J, Schneider JG, Uluckan O, et al. The ADP Receptor P2RY12 Regulates Osteoclast Function and Pathologic Bone Remodeling. J Clin Invest (2012) 122:3579-92. doi: 10.1172/JCI38576

43. Idris A, Mrak E, Greig I, Guidobono F, Ralston SH, van 't Hof R. ABD56 Causes Osteoclast Apoptosis by Inhibiting the Nfkb and ERK Pathways. Biochem Biophys Res Commun (2008) 371:94-8. doi: 10.1016/j.bbrc. 2008.04.014

44. Wang N, Robaye B, Agrawal A, Skerry TM, Boeynaems J-M, Gartland A. Reduced Bone Turnover in Mice Lacking the P2Y13 Receptor of ADP. Mol Endocrinol (2012) 26:142-52. doi: 10.1210/me.2011-1083

45. Biver G, Wang N, Gartland A, Orriss I, Arnett TR, Boeynaems J-M, et al. Role of the P2Y13 Receptor in the Differentiation of Bone Marrow Stromal Cells Into Osteoblasts and Adipocytes. Stem Cells (2013) 31:2747-58. doi: 10.1002/ stem.1411

46. Wang N, Rumney RMH, Yang L, Robaye B, Boeynaems J-M, Skerry TM, et al. The P2Y13 Receptor Regulates Extracellular ATP Metabolism and the Osteogenic Response to Mechanical Loading. J Bone Miner Res (2013) 28:1446-56. doi: $10.1002 / \mathrm{jbmr} .1877$

47. Wang N, Robaye B, Gossiel F, Boeynaems J-M, Gartland A. The P2Y13 Receptor Regulates Phosphate Metabolism and FGF-23 Secretion With Effects on Skeletal Development. FASEB J (2014) 28:2249-59. doi: 10.1096/fj.13243626

48. Lee SA, Park JH, Lee SY. Selective Induction of P2Y14 Receptor by RANKL Promotes Osteoclast Formation. Mol Cells (2013) 36:273-7. doi: 10.1007/ s10059-013-0226-3 
49. Kook S, Cho J, Lee SB, Lee B-C. The Nucleotide Sugar UDP-Glucose Mobilizes Long-Term Repopulating Primitive Hematopoietic Cells. J Clin Invest (2013) 123:3420-35. doi: 10.1172/JCI64060

50. Mikolajewicz N, Komarova SV. Role of UDP-Sugar Receptor P2Y14 in Murine Osteoblasts. Int J Mol Sci (2020) 21:2747. doi: 10.3390/ijms21082747

51. Waldo GL, Harden TK. Agonist Binding and Gq-Stimulating Activities of the Purified Human P2Y1 Receptor. Mol Pharmacol (2004) 65:426-36. doi: 10.1124/mol.65.2.426

52. Jacob PF, Vaz SH, Ribeiro JA, Sebastião AM. P2Y1 Receptor Inhibits GABA Transport Through a Calcium Signalling-Dependent Mechanism in Rat Cortical Astrocytes. Glia (2014) 62:1211-26. doi: 10.1002/glia.22673

53. Ellegaard M, Agca C, Petersen S, Agrawal A, Kruse LS, Wang N, et al. Bone Turnover Is Altered in Transgenic Rats Overexpressing the P2Y2 Purinergic Receptor. Purinergic Signal (2017) 13:545-57. doi: 10.1007/s11302-017-9582-3

54. Wesselius A, Bours MJL, Gartland A, Dagnelie PC. Role of Purinergic Receptor Polymorphisms in Human Bone. Front Biosci (2011) 16:2572-85. doi: $10.2741 / 3873$

55. Wesselius A, Bours MJL, Henriksen Z, Syberg S, Petersen S, Schwarz P, et al. Association of P2Y2 Receptor SNPs With Bone Mineral Density and Osteoporosis Risk in a Cohort of Dutch Fracture Patients. Purinergic Signal (2013) 9:41-9. doi: 10.1007/s11302-012-9326-3

56. Katz S, Boland R, Santillán G. Modulation of ERK $1 / 2$ and P38 MAPK Signaling Pathways by ATP in Osteoblasts: Involvement of Mechanical StressActivated Calcium Influx, PKC and Src Activation. Int J Biochem Cell Biol (2006) 38:2082-91. doi: 10.1016/j.biocel.2006.05.018

57. Katz S, Boland R, Santillán G. Purinergic (ATP) Signaling Stimulates JNK1 But Not JNK2 MAPK in Osteoblast-Like Cells: Contribution of Intracellular $\mathrm{Ca} 2+$ Release, Stress Activated and L-Voltage-Dependent Calcium Influx, PKC and Src Kinases. Arch Biochem Biophys (2008) 477:244-52. doi: 10.1016/ j.abb.2008.06.019

58. Costessi A, Pines A, D’Andrea P, Romanello M, Damante G, Cesaratto L, et al. Extracellular Nucleotides Activate Runx2 in the Osteoblast-Like HOBIT Cell Line: A Possible Molecular Link Between Mechanical Stress and Osteoblasts' Response. Bone (2005) 36:418-32. doi: 10.1016/j.bone.2004.10.016

59. Pines A, Bivi N, Romanello M, Damante G, Kelley MR, Adamson ED, et al. Cross-Regulation Between Egr-1 and APE/Ref-1 During Early Response to Oxidative Stress in the Human Osteoblastic HOBIT Cell Line: Evidence for an
Autoregulatory Loop. Free Radic Res (2005) 39:269-81. doi: 10.1080/ 10715760400028423

60. Gardinier J, Yang W, Madden GR, Kronbergs A, Gangadharan V, Adams E, et al. P2Y2 Receptors Regulate Osteoblast Mechanosensitivity During Fluid Flow. Am J Physiol Physiol (2014) 306:C1058-67. doi: 10.1152/ajpcell. 00254.2013

61. Buckley KA, Hipskind RA, Gartland A, Bowler WB, Gallagher JA. Adenosine Triphosphate Stimulates Human Osteoclast Activity via Upregulation of Osteoblast-Expressed Receptor Activator of Nuclear Factor- $\mathrm{bb}$ Ligand. Bone (2002) 31:582-90. doi: 10.1016/S8756-3282(02)00877-3

62. Kozlow W, Guise TA. Breast Cancer Metastasis to Bone: Mechanisms of Osteolysis and Implications for Therapy. J Mammary Gland Biol Neoplasia (2005) 10:169-80. doi: 10.1007/s10911-005-5399-8

63. Bos JL, De Rooij J, Reedquist KA. Rap1 Signalling: Adhering to New Models. Nat Rev Mol Cell Biol (2001) 2:369-77. doi: 10.1038/35073073

64. Lazarowski ER, Harden TK. UDP-Sugars as Extracellular Signaling Molecules: Cellular and Physiologic Consequences of P2Y14 Receptor Activation. Mol Pharmacol (2015) 88:151-60. doi: 10.1124/mol.115.098756

65. Kringelbach TM, Aslan D, Novak I, Schwarz P, Jørgensen NR. UTP-Induced ATP Release Is a Fine-Tuned Signalling Pathway in Osteocytes. Purinergic Signal (2014) 10:337-47. doi: 10.1007/s11302-013-9404-1

Conflict of Interest: The authors declare that the research was conducted in the absence of any commercial or financial relationships that could be construed as a potential conflict of interest.

Publisher's Note: All claims expressed in this article are solely those of the authors and do not necessarily represent those of their affiliated organizations, or those of the publisher, the editors and the reviewers. Any product that may be evaluated in this article, or claim that may be made by its manufacturer, is not guaranteed or endorsed by the publisher.

Copyright (c) 2022 Zhou, Arredondo and Wang. This is an open-access article distributed under the terms of the Creative Commons Attribution License (CC BY). The use, distribution or reproduction in other forums is permitted, provided the original author(s) and the copyright owner(s) are credited and that the original publication in this journal is cited, in accordance with accepted academic practice. No use, distribution or reproduction is permitted which does not comply with these terms. 